\title{
Influence of Patient and Hospital Characteristics on the Performance of Direct Reconstruction after Mastectomy
}

\author{
Einfluss von Patientinnen- und Krankenhausmerkmalen auf \\ die Durchführung einer direkten Rekonstruktion nach Mastektomie
}

Authors

Affiliations
J. Hartrampf ${ }^{1}$, L. Ansmann ${ }^{1}$, S. Wesselmann ${ }^{2}$, M. W. Beckmann ${ }^{3}$, H. Pfaff ${ }^{1}$, C. Kowalski ${ }^{1,2}$

${ }^{1}$ IMVR - Institut für Medizinsoziologie, Versorgungsforschung und Rehabilitationswissenschaft der Humanwissenschaftlichen Fakultät und der Medizinischen Fakultät, Universität zu Köln, Köln

${ }^{2}$ Bereich Zertifizierung, Deutsche Krebsgesellschaft, Berlin

${ }^{3}$ Frauenklinik, Universitätsklinikum Erlangen, Erlangen

\section{Key words}

- immediate reconstruction

- certified breast cancer centres

- multilevel analysis

- minimum numbers

\section{Schlüsselwörter}

- direkte Rekonstruktion

- zertifizierte Brustkrebszentren

- Mehrebenenanalyse

- Mindestmengen

Deutschsprachige Zusatzinformationen online abrufbar unter: www.thieme-connect.de/ ejournals/toc/gebfra received 30.9.2014 revised 17.11.2014 accepted 17.11.2014

Bibliography

Dol http://dx.doi.org/ 10.1055/s-0034-1383400

Geburtsh Frauenheilk 2014; 74: 1128-1136 @ Georg Thieme Verlag KG Stuttgart · New York . ISSN 0016-5751

\section{Correspondence}

Dr. Christoph Kowalski

Deutsche Krebsgesellschaft Bereich Zertifizierung

Kuno-Fischer-Straße 8

14057 Berlin

kowalski@krebsgesellschaft.de

\section{Abstract \\ $\nabla$}

Aim: International studies have shown that the performance of a direct (or immediate) reconstruction (DR) after mastectomy is associated with patient (e.g., socio-economic status, insurance status, age) and hospital (number of cases, teaching status) characteristics. The present article addresses the question if such relationships also exist in Germany.

Material and Methods: The results of a nationwide questionnaire to the patients of certified breast cancer centres were coupled with the clinical features of the patients and the characteristics of the hospital. Predictors for receiving a DR (vs. delayed or no reconstruction) were estimated by means of a logistic multilevel model for a sample of 1165 patients from 105 certified locations. Results: Substantial differences between the treating hospitals were found (intraclass correlation coefficient null model: 0.195) which can in part be explained by the total model (total model: 0.169 ). Patients with the following features are more likely to receive a DR: younger age, private health insurance, secondary school leaving certificate (vs. primary school leaving certificate), lower stage and acquisition of more information about reconstruction. ASA and partnership status are not statistically significantly related with DR. DR is more likely to be performed in hospitals with higher caseload of patients with primary breast cancer. Teaching status, operations per surgeon and urbanity of the location are not related to receiving a DR.

Conclusions: Non-clinical features of the patients and the primary case number are associated with the performance of a DR, this poses questions concerning reasons and the equality of health care.

\section{Zusammenfassung \\ $\nabla$}

Ziel: Internationale Studien zeigen, dass die Durchführung einer direkten Rekonstruktion (DR) nach Mastektomie mit Patientinnen- (z.B. sozioökonomischer Status, Versicherungsstatus, Alter) und Krankenhausmerkmalen (Fallzahl, Lehrstatus) assoziiert ist. Diese Arbeit untersucht, ob sich derartige Zusammenhänge auch für Deutschland zeigen lassen.

Material und Methode: Ergebnisse einer bundesweiten Patientinnenbefragung in zertifizierten Brustkrebszentren werden mit klinischen Merkmalen der Patientinnen und Merkmalen der Krankenhäuser verknüpft. Prädiktoren des Erhalts einer DR (vs. spätere/keine Rekonstruktion) werden mittels logistischer Mehrebenenmodelle für eine Stichprobe von 1165 Patientinnen aus 105 zertifizierten Standorten geschätzt.

Ergebnisse: Es zeigen sich erhebliche Unterschiede zwischen den behandelnden Krankenhäusern (Intraklassenkorrelationskoeffizient Nullmodell: $0,195)$, die teilweise durch das Gesamtmodell erklärt werden können (Gesamtmodell: 0,169). Patientinnen mit folgenden Merkmalen erhalten wahrscheinlicher eine DR: geringeres Alter, private Krankenversicherung, Realschulabschluss (vs. Haupt-/Volksschulabschluss), niedrigeres Stadium und Erhalt von mehr Informationen über Rekonstruktion. ASA und Kohabitationsstatus sind nicht statistisch signifikant mit DR assoziiert. DR wird mit steigender Primärfallzahl pro Krankenhaus wahrscheinlicher durchgeführt. Lehrstatus, Operationen pro Operateur und Urbanität des Standorts hängen nicht mit dem Erhalt einer DR zusammen.

Schlussfolgerung: Nichtklinische Merkmale der Patientinnen und die Primärfallzahl sind mit der Durchführung einer DR assoziiert, was Fragen nach den Ursachen und der Versorgungsgerechtigkeit aufwirft. 


\section{Introduction}

$\nabla$

About one third of the estimated 72000 women diagnosed in Germany for the first time with breast cancer each year [1,2] undergo a mastectomy which may be followed by a direct (immediate) reconstruction (DR) to restore the body image. The decision for a direct or a delayed reconstruction is in principle dependent on the patient's situation [3]. Studies point to positive emotional effects of the DR for the patient, however as yet there are no (randomised) trials [4-6]. Begum et al. in a qualitative study identified, among others, misgivings regarding body image and the burden of only a single operation as the expressed reason for a DR from the patient's side [7]. Among others, a delayed onset of postoperative therapy may be a reason against DR [8-13]. In the case of a planned radiotherapy subsequent to the mastectomy, for example, a later reconstruction with autologous tissue may be undertaken. The proportion of patients receiving a DR is increasing, this is especially evident in USA and Canada $[9,14]$.

According to the German S3 guidelines, all patients should be informed about the possibilities for a primary or secondary reconstruction [3]. The requirements for certification by the German Cancer Society (Deutsche Krebsgesellschaft [DKG]) and the German Society for Senology (Deutsche Gesellschaft für Senologie [DGS]) call for comprehensive counselling of the patients by the treating centres [15]. This is based on studies that confirm for those patients who actively decide for a secondary reconstruction there is often a rather unclarified patient situation which can be recognised in the decision-making background. This is possibly also accompanied by anxiety which then leads to the decision against a direct reconstruction [16]. As demonstrated by Fernandez-Delgado et al. [4] in a study on satisfaction with and the mental consequences of a direct reconstruction, many women who have experienced other treatments would retrospectively have preferred the direct reconstruction $(87.27 \%$ of those who underwent later reconstruction). The S3 guidelines recommend that without exception the patient should be informed about all advantages and disadvantages with regard to reconstruction options and that the patient's subsequent decision as well as the actually performed reconstruction be documented. There is no target value for the number of reconstructions or requirements with regard to the time point of the reconstruction $[2,15]$.

Foreign studies have reported that the decision for or against a DR is not only related to clinical factors but also to other characteristics of the patient and that there are, in part, large differences between the treating institutions. Thus, a British study came to the conclusion that the performance of a DR varies considerably between hospitals and that the operation is more frequent among white women and women from more affluent districts [17]. Data from the USA reveal, among others, a higher rate of DR for younger or privately insured women, those from urban residential areas and from residential areas with higher average household incomes or higher average levels of education as well as patients who are treated in teaching hospitals [18-20]. In Australia, besides the clinical features, among others a higher social status, a private health insurance and surgeons with a higher number of cases are predictors for receiving a DR [21].

Finally, an investigation in the USA presented by Hershman et al. in 2012 demonstrated associations between the performance of a DR and the hospital and patient characteristics. Accordingly, in a multivariate model, Afro-American, older, or married women, women living in rural districts and women more affected by co- morbidities underwent a DR less frequently. Privately and Medicare insured women (as opposed to self-payers) received a DR more often as did patients in hospitals with a higher yearly number of mastectomies and higher number of mastectomies per surgeon and those treated in hospitals with a larger number of beds [22].

In spite of the high academic interest in this topic, as yet no such studies have been carried out in Germany. Our contribution supplements the predictors considered in the study of Hershman et al. with information regarding reconstruction and self-help groups, contact to self-help groups and further patient characteristics (ASA, education, grading, uni-/bilateral findings). With the help of survey data from certified breast cancer centres, we have investigated which factors are associated with the performance of DR in Germany.

\section{Materials and Methods \\ $\nabla$}

\section{Data acquisition}

The data evaluated in this study originated from a patient questionnaire coupled with a survey of centres regarding structural and procedural characteristics (so-called "key informant survey") ( Fig. 1). The surveys and the data protection concept were approved by the Ethics Commission of the medical faculty of Cologne University. The data were supplemented by population figures of the towns or cities in which the participating hospitals were located [23].

\section{Patient survey}

The patient data used in this contribution were collected between March and November 2010 by means of a questionnaire sent by post to women who had previously been inpatients in breast cancer centres certified according to the criteria of DKG and DGS [24]. During the acquisition period the agreement declarations of all their patients who had previously been informed about the survey (inclusion criteria: operation during the hospital stay, primary malignant finding, ICD code of the confirmed diagnosis C50.x or D05.x) together with the clinical characteristics of the respective patients were submitted weekly to the institution performing the survey. The survey was oriented on the Total Design Method according to Dillman [25] with two written reminders. We used the Cologne Patient Questionnaire for Breast Cancer (CPQ-BC), which assesses key dimensions of inpatient care and has been in use in a practically identical version since 2006, also in centres certified according to the requirements of the province North Rhine-Westphalia [26].

\section{Key informant survey}

The key informant survey, from which information on the hospital characteristics originate was also performed in the breast cancer centres certified according to the criteria of DKG and DGS [27]. The aim of the survey performed in 2011 was to investigate, beside the already acquired patient perspectives, also perspectives of the health-care supplier and thus to enable comparisons to be made of the structures and processes in the breast cancer centres. The questionnaire contains items on the implementation status of the centre concept as well as structural characteristics of the hospital. They are mostly factual questions. The person in the breast centre to whom the questionnaire was addressed (mostly the coordinator or head of the centre) was requested to consult his/her colleagues if he/she was unable to answer individual 


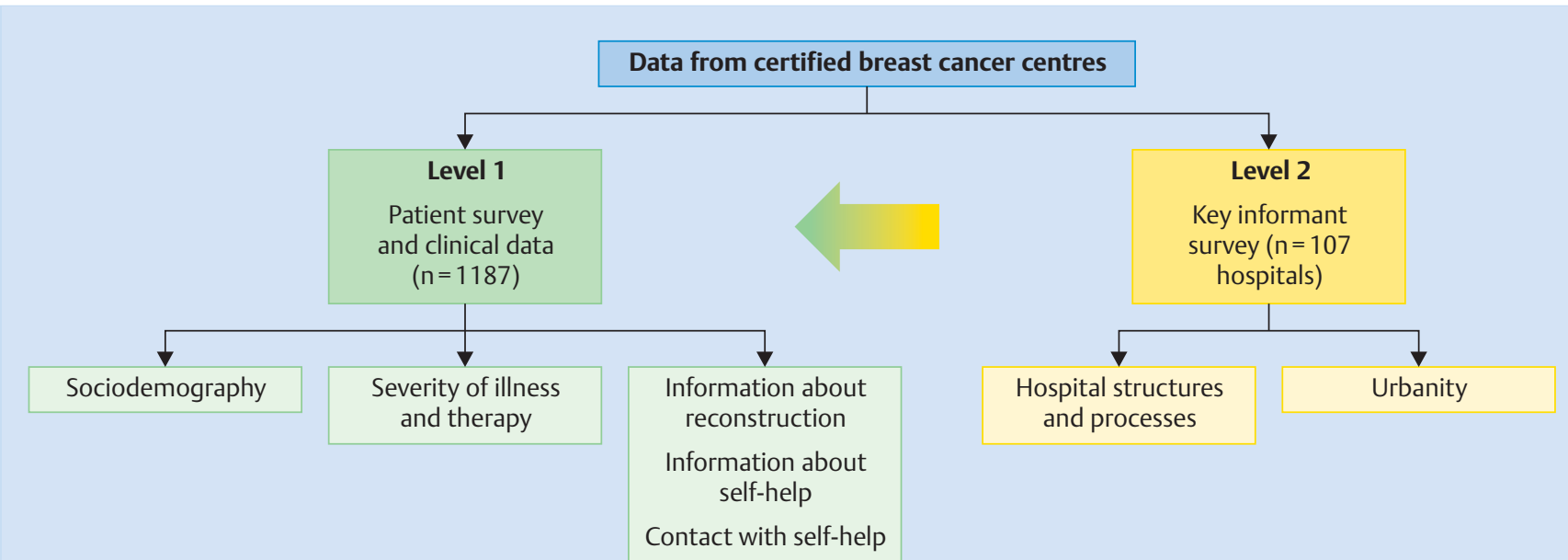

Fig. 1 Data sources.

questions. This voluntary survey was also performed following the Total Design Method according to Dillman (1978).

\section{Variables}

All variables used in the analysis were categorised when they were not already available as categorical variables. The data on the dependent variable "direct reconstruction" (yes/no) were obtained from the answers on the type of operation in the clinical characteristics of the patient. The age of the patient was considered as a continuous variable for the bivariate analysis and was categorised into six classes (18-39, 40-49, 50-59, 60-69, 70-79 and over 80 years) for the regression model. The data on health insurance were summarised into three groups (statutory insurance, private insurance, and statutory insurance with additional private insurance). The variable cohabitation status has two response traits (living together with spouse or partner: yes, no). The highest school leaving certificate was represented with four categories (no leaving certificate, junior school certificate, secondary school certificate, technical college/high school certificate). From the data on tumour size, lymph node attack and metastases (TNM classification) taken from the patient's clinical findings, the staging according to UICC [28] was deduced with five categories (stage 0 to IV). The grading (I, II, III) taken from the clinical findings was treated in unchanged form as a categorical variable. The five categories of the ASA classification [29] to assess the general physical condition were summarized into three categories $(1,2,3-5)$ for the regression model, but not for the bivariate analysis. The information on the afflicted breast was recoded into one variable with two categories (both sides, only one side affected). To check the relationship of the information about the reconstruction with the dependent variables, the following items were used: "to what extent did the physician in the hospital give you information about the following topics: on removal of the breast (mastectomy); about possibilities for reconstruction of the breast". The five answer categories in the questionnaire ranged from "no information" to "very much information". Information about self-help groups and contact to selfhelp groups were recorded as variables on the basis of the following questions in the patient questionnaire: "Did anyone in the hospital inform you about self-help groups?”; “Did you during your hospital stay come into contact with self-help groups?" (response format: yes, no).

From the key informant survey, details about the hospital characteristics were retrieved. The teaching status of the hospital was represented with a dichotomous variable (yes, no). The number of operations of primary cases per year was categorised into four groups (up to $100,101-200,201-300$, more than 300 ). The ratio of the number of main surgeons and the number of operations on primary breast cancers formed the basis for the variable operations per surgeon which encompassed the averaged experience of the surgeons at those locations. The determined ratio of the hospitals were categorised into "less than 50", "50 to 99" and "100 or more" operations per year. To determine the urbanity of the hospital location, the numbers of residents in the communities of the participating hospitals were acquired. The numbers were taken from the municipal directories of the Federal Statistical Office on the basis of the 2011 census [22] and grouped into four characteristics (small towns $[<20000$ population \{pop\}], medium-sized towns/cities [20000 to 100000 pop], large cities [>100000 to 1000000 pop] and million people cities [>1000000 pop]).

\section{Statistical analysis}

To analyse the relationships between the variables, a bivariate correlation analysis was undertaken as the first step. Variables that did not reveal any significant relationships with DR were excluded from further analyses. As prerequisite for the regression analysis the remaining variables were subjected to a multicolinearity test by a variance inflation factor (VIF) in order to exclude multicollinearity.

In a second step logistic multilevel models with DR as dependent variable were estimated. The multilevel analysis is an appropriate analytical method for the present hierarchical data structure (patients belonging to different hospitals). We used the full maximum likelihood estimation procedure. The maximum likelihood method (ML) is one of the most frequently used methods in multilevel analyses and, especially for large samples, is robust against minor violations of the prerequisites [30].

At first a null model was calculated in which, apart from the dependent variable, no other factors were included. From the variance component determined in this model the intraclass correla- 
tion coefficient (ICC) can be calculated with the help of the formula proposed by Snijders and Bosker for hierarchical logistic regression models [31]. In a first model the independent variables at the patient level (level 1) were included and in a second model the independent variables at the hospital level (level 2) were added. All variables were taken uncentred into the model. Subsequently, as a measure of variance explanation, $R_{2}^{2}$ was calculated on the basis of the ICC of model 2. The larger $\mathrm{R}_{2}^{2}$ is, the more can the variance in the dependent variable be explained by the model.

No imputations were undertaken for missing values. Cases with missing values in the dependent variables were excluded from the analyses. In order to avoid listwise deletion in the regression models, the models included dummy variables for missing values, for the sake of parsimonity these are not represented in the results. The descriptive and bivariate analyses were done with the help of the statistical software IBM SPSS Version 22. Calculations on the multilevel analysis were done with HLM 6.05.

\section{Results}

$\nabla$

\section{Sample}

160 of the 251 of at that time certified operation locations (from 128 of 195 certified breast cancer centres) participated in the patient questionnaire. The locations that did not participate did not differ from the participating ones with regard to ownership, teaching status and case numbers [32]. 1128 of 9354 patients enrolled by the hospitals $(12 \%)$ refused to participate. 7301 of the 8226 patients who agreed to participate and to whom the questionnaire was sent by post returned the completed questionnaire (88.76\%) [24]. 111 of 160 locations participating in the patient survey also took part in the key informant survey (69.4\%). In this survey again there were no significant differences between the participating and the non-participating hospitals with regard to ownership, size and teaching status [32]. 5024 patients who participated in the survey were treated in these 111 hospitals. 1219 of the 5024 (24.3\%) underwent a mastectomy. The 19 male patients were excluded as also were 13 questionnaires with missing information as to gender. The remaining 1187 were treated at a total of 107 surgical locations and served as the sample for the subsequent analyses.

\section{Descriptive results - differences \\ in patient characteristics}

Of the 1187 patients who underwent mastectomies, 249 received a DR (21.0\%). O Table 1 to 3 show the frequency distributions of patient characteristics for all the mastectomy patients and separately for those who underwent a DR. O Table 4 shows the frequency distributions for the hospital characteristics of all 107 participating surgical locations.

$55.6 \%$ of all mastectomy patients were 60 or more years old, in the bivariate analysis the rate of patients undergoing direct reconstruction declines with increasing age. Among those with private insurance, $31.5 \%$ underwent a DR, for those with statutory insurance only, the corresponding rate was $19.5 \%$. In bivariate analysis the DR rate for patients living alone was $15.2 \%$, for those living with a partner it was $24.1 \%$. Among patients with secondary school leaving certificates and those with high school leaving certificates, the DR rate was almost three times higher than those for patients with junior school or no leaving certificates. In bivariate analysis the DR rate decreased with increasing stage and was highest with $29.6 \%$ for patients with ASA 1 .

Table 1 Distribution of sociodemographic characteristics of the patients and the rates of direct reconstruction.

\begin{tabular}{|c|c|c|c|c|}
\hline Characteristic & Number & $\begin{array}{l}\text { Proportion } \\
\text { in sample (\%) }\end{array}$ & $\begin{array}{l}\text { Number of direct } \\
\text { reconstructions }\end{array}$ & $\begin{array}{l}\text { Rate of direct } \\
\text { reconstructions (\%) }\end{array}$ \\
\hline \multicolumn{5}{|l|}{ Age } \\
\hline - 18-29 years & 14 & 1.2 & 7 & 50.0 \\
\hline - 30-39 years & 52 & 4.4 & 23 & 44.2 \\
\hline > $40-49$ years & 201 & 17.1 & 78 & 38.8 \\
\hline - $50-59$ years & 253 & 21.6 & 71 & 28.1 \\
\hline - 60-69 years & 286 & 24.4 & 49 & 17.1 \\
\hline - 70-79 years & 268 & 22.8 & 17 & 6.3 \\
\hline - 80 and more years & 99 & 8.4 & 1 & 1.0 \\
\hline missing & 14 & & & \\
\hline \multicolumn{5}{|l|}{ Insurance status } \\
\hline only statutory health insurance & 973 & 83.7 & 190 & 19.5 \\
\hline $\begin{array}{l}\text { statutory health insurance with additional } \\
\text { private insurance }\end{array}$ & 101 & 8.7 & 29 & 28.7 \\
\hline private health insurance & 89 & 7.7 & 28 & 31.5 \\
\hline missing & 24 & & & \\
\hline \multicolumn{5}{|l|}{ Partner/spouse } \\
\hline$\checkmark$ yes & 788 & 67.4 & 190 & 24.1 \\
\hline$>$ no & 381 & 32.6 & 58 & 15.2 \\
\hline missing & 18 & & & \\
\hline \multicolumn{5}{|l|}{ School education } \\
\hline no leaving certificate & 32 & 2.8 & 4 & 12.5 \\
\hline - junior school leaving certificate & 518 & 45.9 & 61 & 11.8 \\
\hline - secondary school leaving certificate & 335 & 29.7 & 97 & 29.0 \\
\hline - technical college/high school leaving certificate & 244 & 21.6 & 76 & 31.1 \\
\hline missing & 58 & & & \\
\hline Total & 1187 & & 249 & 21.0 \\
\hline
\end{tabular}


Table 2 Distribution of patient characteristics regarding findings and severity of disease as well as rates of direct reconstruction.

\begin{tabular}{|c|c|c|c|c|}
\hline Characteristic & Number & $\begin{array}{l}\text { Proportion } \\
\text { in the sample (\%) }\end{array}$ & $\begin{array}{l}\text { Number of direct } \\
\text { reconstructions }\end{array}$ & $\begin{array}{l}\text { Rate of direct } \\
\text { reconstructions (\%) }\end{array}$ \\
\hline \multicolumn{5}{|l|}{ Stage (UICC) } \\
\hline$>0$ & 96 & 9.3 & 37 & 38.5 \\
\hline - 1 & 224 & 21.7 & 80 & 35.7 \\
\hline$>$ II & 385 & 37.3 & 69 & 17.9 \\
\hline > III & 253 & 24.5 & 30 & 11.9 \\
\hline > IV & 74 & 7.2 & 5 & 6.8 \\
\hline missing & 155 & & & \\
\hline \multicolumn{5}{|l|}{ Grading } \\
\hline - G1 & 97 & 8.7 & 23 & 23.7 \\
\hline - $\mathrm{G} 2$ & 644 & 57.7 & 126 & 19.6 \\
\hline$>\mathrm{G} 3$ & 375 & 33.6 & 79 & 21.1 \\
\hline missing & 71 & & & \\
\hline \multicolumn{5}{|l|}{ ASA classification } \\
\hline - 1 : normal, healthy patient & 433 & 37.0 & 128 & 29.6 \\
\hline - 2: minor general illness & 544 & 46.5 & 103 & 18.9 \\
\hline - 3 : severe general illness & 191 & 16.3 & 11 & 5.8 \\
\hline - 4: life-threatening general illness & 2 & 0.2 & 0 & 0.0 \\
\hline 5: moribund patient & 1 & 0.1 & 0 & 0.0 \\
\hline missing & 16 & & & \\
\hline \multicolumn{5}{|l|}{ Bilaterally affected breast } \\
\hline yes & 51 & 4.3 & 9 & 17.6 \\
\hline$>$ no & 1134 & 95.7 & 239 & 21.1 \\
\hline missing & 2 & & & \\
\hline
\end{tabular}

Table 3 Distribution of patient characteristics regarding information about reconstruction as well as information on and contact with self-help groups and rates of direct reconstruction.

\begin{tabular}{|c|c|c|c|c|}
\hline Characteristic & Number & $\begin{array}{l}\text { Proportion } \\
\text { in the sample (\%) }\end{array}$ & $\begin{array}{l}\text { Number of direct } \\
\text { reconstructions }\end{array}$ & $\begin{array}{l}\text { Rate of direct } \\
\text { reconstructions (\%) }\end{array}$ \\
\hline \multicolumn{5}{|c|}{ Information about reconstruction } \\
\hline no information & 92 & 10.0 & 3 & 3.3 \\
\hline - very little information & 64 & 6.9 & 6 & 9.4 \\
\hline - little information & 133 & 14.4 & 30 & 22.6 \\
\hline much information & 192 & 20.8 & 54 & 28.1 \\
\hline very much information & 442 & 47.9 & 131 & 29.6 \\
\hline missing & 264 & & & \\
\hline \multicolumn{5}{|c|}{ Information about self-help groups } \\
\hline > yes & 580 & 59.0 & 136 & 23.4 \\
\hline$>$ no & 403 & 41.0 & 80 & 19.9 \\
\hline missing & 204 & & & \\
\hline \multicolumn{5}{|c|}{ Contact with self-help groups } \\
\hline > yes & 82 & 8.7 & 15 & 18.3 \\
\hline no & 857 & 91.3 & 179 & 20.9 \\
\hline missing & 248 & & & \\
\hline
\end{tabular}

The DR rate was higher for those patients who reported to have received more information than among those who reported to have received little or no information. $59 \%$ of all mastectomy patients received information about self-help groups. For $8.7 \%$ of the patients contact to a self-help group was realised during the hospital stay. The reconstruction rate of those who had contact to self-help groups was $18.3 \%$, and thus somewhat lower in bivariate analysis than that for those who had no contact.

\section{Descriptive results - differences}

in hospital characteristics

Of the 107 hospitals $85 \%$ were teaching hospitals. In most of the hospitals between 101 and 200 primary cases were operated each year, 13 hospitals treated less than 100 cases per year. The number of operations per senior surgeon per year was between
50 and 99 in two thirds of the hospitals, in 25 hospitals it was less than 50 operations per surgeon and in 10 hospitals it was 100 or more. The large majority of the hospitals were located in towns or cities with populations of 20000 to 100000 residents, 42 hospitals are in large city locations, 9 in small towns and 7 in Germany's million people cities.

\section{Correlations with patient characteristics}

- Table 5 shows the relationships between the independent variables at the patient level and the dependent variables. For young age, statutory health insurance with additional private insurance, private health insurance (each in comparison with statutory health insurance), living in a partnership, higher educational level and receiving more information about breast reconstruction, significantly positive relationships with receiving a DR were 
Table 4 Hospital characteristics: structures, processes and urbanity.

\begin{tabular}{|c|c|c|}
\hline Nature of the characteristic & $\begin{array}{l}\text { Number } \\
(n=107)\end{array}$ & Valid (\%) \\
\hline \multicolumn{3}{|l|}{ Teaching hospital } \\
\hline ves & 91 & 85.0 \\
\hline no & 16 & 15.0 \\
\hline missing & 0 & \\
\hline \multicolumn{3}{|l|}{ Operations per year } \\
\hline up to 100 & 13 & 12.4 \\
\hline > $101-200$ & 50 & 47.6 \\
\hline > 201-300 & 30 & 28.6 \\
\hline - 301-400 & 7 & 6.7 \\
\hline - 400 and more & 5 & 4.8 \\
\hline missing & 2 & \\
\hline \multicolumn{3}{|c|}{ Surgeon case numbers (operations per year) } \\
\hline less than 50 & 25 & 23.8 \\
\hline > 50-99 & 70 & 66.7 \\
\hline > 100 and more & 10 & 9.5 \\
\hline missing & 2 & \\
\hline \multicolumn{3}{|c|}{ Urbanity of hospital location (population) } \\
\hline small town $(<20000)$ & 9 & 8.4 \\
\hline $\begin{array}{l}\text { medium-sized town/city } \\
(20000-100000)\end{array}$ & 49 & 45.8 \\
\hline - large city $(<100000-1000000)$ & 42 & 39.3 \\
\hline - million people city (> 1000000$)$ & 7 & 6.5 \\
\hline missing & 0 & \\
\hline
\end{tabular}

found. Higher stages and higher ASA classifications had significant negative correlations with DR. It is seen that obtaining information about self-help groups and contact to self-help groups are not significantly associated with DR. Thus, these variables were excluded from the further analyses. The same is true for the variable uni- or bilateral findings. Correlation analyses of the remaining independent variables among each other did not reveal any relationships that could be considered as critically high $(>0.6)$ (data not shown). Also the VIF values did not provide any indication for multicollinearity.

\section{Results of the multilevel analysis - \\ differences between the hospitals}

Due to the absence of data about case numbers, two hospitals were excluded from the further analysis so that in total $1165 \mathrm{pa}-$ tients from 105 hospitals were taken into consideration in the multilevel analysis. OTable 6 shows the results of the logistic multilevel analysis. In the null model the ICC amounted to 0.19. A relatively large portion of the variance in the dependent variables can thus be attributed to differences between the hospitals. In model 1 statistically significant relationships with DR are seen for young age, private insurance status (compared to statutory insurance), secondary school leaving certificate (compared to junior school leaving certificate), lower stage and more information about reconstruction. This was not the case with regard to living with a partner and the general health condition (ASA).

Hospital characteristics are included in model 2 in order to determine possible relationships between the hospital characteristics with receiving a DR concomitantly to relationships at the patient level. All significant relationships in model 1 were also found in model 2 . Among the newly included variables a significant result is seen for the two categories concerning the number of operated breast cancer patients in the hospital. For patients in hospitals with over 200 up to 300 operations per year there is an approximately two-fold higher chance to receive a DR in comparison to
Table 5 Correlations between patient characteristics and undergoing direct reconstruction.

\begin{tabular}{|l|l|}
\hline Variables & $\begin{array}{c}\text { Performance of a } \\
\text { direct reconstruction } \\
\text { correlation (significance) } \\
0.341^{* *}(0.000)\end{array}$ \\
\hline Age & $-0.076^{* *}(0.009)$ \\
\hline Insurance status & $0.058^{*}(0.046)$ \\
\hline only statutory health insurance & $0.073^{*}(0.020)$ \\
\hline statutory health insurance + & $-0.045(0.124)$ \\
\hline additional private insurance & $0.102^{* *}(0.000)$ \\
\hline private health insurance & $0.212^{* *}(0.000)$ \\
\hline missing & $-0.251^{* *}(0.000)$ \\
\hline (Marital) partnership & $0.000(0.992)$ \\
\hline School education & $-0.201^{* *}(0.000)$ \\
\hline Stage (UICC) & $-0.017(0.556)$ \\
\hline Grading & $0.172^{* *}(0.000)$ \\
\hline ASA classification & $0.043(0.180)$ \\
\hline Bilaterally affected breast & $-0.018(0.579)$ \\
\hline Information about reconstruction & \\
\hline Information about self-help groups & \\
\hline Contact to self-help groups &
\end{tabular}

significant at * level $0.05,{ }^{* *}$ level 0.01

the reference group (101-200 operations). For patients in hospitals with more than 300 operations the probability is substantially higher. There are no significant relationships for teaching status of the hospital, the surgeon's yearly case numbers and the urbanity of the hospital's location. The degree of variance explanation by the factors included in model $2\left(\mathrm{R}_{2}^{2}\right)$ amounted to 0.131 .

\section{Discussion}

\section{$\nabla$}

A direct reconstruction after a mastectomy is significantly more frequently undertaken in Germany for women with a first diagnosis of breast cancer for younger, privately insured and less severely ill patients (lower stage). In addition, patients with secondary school leaving certificates receive a DR significantly more often than those with junior school leaving certificates. This is not statistically significant for patients with high school leaving certificates compared to those with junior school leaving certificates. These results essentially agree with those of the study by Hershman and colleagues [22] as well as those of older studies from the USA on DR and should be viewed against the background of other studies in which the performance of a reconstruction after mastectomy was associated not only with severity of disease and age [8,33-37], but also, for example, with education $[8,38]$ and insurance status $[35,36]$ and thus is socially unequally distributed. Comparisons between different countries, however, are of limited use due to differences in the insurance and education systems. No relationships were found in the multivariable model for cohabitation status and ASA classification. An explanation of the age effect could be that older patients, as assumed by Roder et al. (2013), are more willing to accept a change of their body image. However, Sisco et al. (2012) observed over the course of time a decreasing relationship with age which is suggestive of an increasing relevance of body image also in advanced age. The relationships with insurance status, education and income point to a differentiated utilisation due to social status and pose the questions about the equality of health care and a universalistic treatment [39] by health-care providers. Similar 
Table 6 Results of the multilevel analysis - relationships between the probability for receiving a direct reconstruction and the characteristic at the patient and hospital levels.

\begin{tabular}{|c|c|c|}
\hline & Model 1 & Model 2 \\
\hline & OR (95\% Cl) & OR (95\% Cl) \\
\hline Intercept & $0.16(0.09 ; 0.29)$ & $0.12(0.05 ; 0.30)$ \\
\hline \multicolumn{3}{|l|}{ Patient level $(n=1165)$} \\
\hline \multicolumn{3}{|l|}{ Age (ref.: 60-69 years) } \\
\hline - $18-39$ years & $4.36(2.09 ; 9.09)$ & $4.45(2.12 ; 9.32)$ \\
\hline - 40-49 years & $1.07(0.25 ; 4.51)$ & $1.01(0.24 ; 4.27)$ \\
\hline - 50-59 years & $1.95(1.18 ; 3.24)$ & $1.97(1.18 ; 3.28)$ \\
\hline - 70-79 years & $0.39(0.20 ; 0.78)$ & $0.38(0.19 ; 0.77)$ \\
\hline$\geq 80$ years & $0,07(0,01 ; 0,57)$ & $0,07(0,01 ; 0,56)$ \\
\hline \multicolumn{3}{|l|}{ Insurance status (ref.: statutory insurance only) } \\
\hline statutory insurance + additional private insurance & $1.01(0.55 ; 1.87)$ & $0.92(0.49 ; 1.72)$ \\
\hline private health insurance & $2,07(1,07 ; 3,99)$ & $1,97(1,01 ; 3,81)$ \\
\hline \multicolumn{3}{|l|}{ (Marital) partnership (ref.: yes) } \\
\hline no no & $0.98(0.65 ; 1.49)$ & $0.96(0.63 ; 1.46)$ \\
\hline \multicolumn{3}{|l|}{ School education (ref.: junior school leaving certificate) } \\
\hline no leaving certificate & $0.97(0.24 ; 3.91)$ & $1.05(0.26 ; 4.24)$ \\
\hline secondary school leaving certificate & $1.58(1.00 ; 2.48)$ & $1.62(1.02 ; 2.56)$ \\
\hline - technical college/high school leaving certificate & $1.39(0.83 ; 2.35)$ & $1.36(0.81 ; 2.30)$ \\
\hline \multicolumn{3}{|l|}{ stage (UICC) (ref.: stage II) } \\
\hline$>0$ & $3.08(1.68 ; 5.65)$ & $3.07(1.67(5.65)$ \\
\hline$\Rightarrow 1$ & $2.25(1.41 ; 3.59)$ & $2.26(1.41 ; 3.61)$ \\
\hline > III & $0.46(0.26 ; 0.79)$ & $0.45(0.26 ; 0.78)$ \\
\hline$\Rightarrow \mathrm{IV}$ & $0.44(0.15 ; 1.29)$ & $0.42(0.14 ; 1.23)$ \\
\hline \multicolumn{3}{|l|}{ ASA classification (ref.: ASA 2) } \\
\hline - ASA 1 & $0.90(0.59 ; 1.37)$ & $0.86(0.56 ; 1.31)$ \\
\hline ASA 3-5 & $0,55(0,24 ; 1,26)$ & $0.55(0.24 ; 1.26)$ \\
\hline \multicolumn{3}{|c|}{ Information about reconstruction (ref.: very much information) } \\
\hline no information & $0.18(0.05 ; 0.62)$ & $0.17(0.05 ; 0.62)$ \\
\hline very little information & $0.23(0.09 ; 0.63)$ & $0.23(0.08 ; 0.64)$ \\
\hline little information & $0.56(0.32 ; 0.97)$ & $0.56(0.32 ; 0.98)$ \\
\hline much information & $0.81(0.51 ; 1.28)$ & $0.82(0.51 ; 1.30)$ \\
\hline \multicolumn{3}{|l|}{ Hospital level $(n=105)$} \\
\hline Teaching hospital (ref.: no) & & $0.93(0.45 ; 1.93)$ \\
\hline \multicolumn{3}{|l|}{ Operations per year (ref.: 101-200) } \\
\hline up to 100 & & $1.28(0.49 ; 3.38)$ \\
\hline - $201-300$ & & $2.09(1.08 ; 4.04)$ \\
\hline more than 300 & & $2.81(1.04 ; 7.59)$ \\
\hline \multicolumn{3}{|l|}{ Surgeon's case number (ref.: 50-99 OPs per year) } \\
\hline - less than 50 & & $1.37(0.65 ; 2.89)$ \\
\hline 100 and more & & $0.44(0.15 ; 1.29)$ \\
\hline \multicolumn{3}{|c|}{ Hospital location according to urbanity (ref.: $20000-100000$ pop) } \\
\hline small town $(<20000)$ & & $0.47(0.14 ; 1.64)$ \\
\hline - large town/city (20000-100000) & & $1.05(0.58 ; 1.88)$ \\
\hline million people city $(<1000000)$ & & $1.79(0.62 ; 5.16)$ \\
\hline ICC (null model 0.195) & 0.201 & 0.169 \\
\hline$R_{2}^{2}$ & & 0.131 \\
\hline
\end{tabular}

Statistically significant results are printed in bold type.

relationships, by the way, can also be found in national healthcare systems, for example, the Canadian system [14].

However, caution is required in the interpretation. The observed differences according to social status and age may be due to different preferences, also according to social status and age, for participation in therapeutic decision making. Studies have shown that better educated and younger patients wish to be involved more in the therapeutic decision making $[40,41]$, which may also be attributed to their higher health literacy [42]. Thus, the younger patients and those with higher social status in our study eventually rather make a claim for primary reconstruction because they are better informed, more strongly express their wishes and have a desire to be more involved. The performance of a DR also depends on the preference of the patient for reconstruc- tion with autologous tissue or a reconstruction using a prosthesis/expander: Whereas the latter operation is associated with a shorter duration of operation and, with the exception of a planned radiotherapy, can be done as a DR, reconstruction using autologous tissue is a protracted process and is thus usually undertaken as a secondary procedure. To date, to the best of our knowledge, no studies have examined the relationships between receiving a DR and the, from the patient's side, perceived amount of information on reconstruction. In the present study the performance of a DR is associated with the receipt of a larger amount of information. This result is suggestive of the major importance of the physician in the decision-making process [7], but cannot be interpreted causally. In future, the relevance of individualised therapy decisions and a corresponding counselling will increase 
further $[43,44]$. Against the background of documentation requirements [45], in which ultimately the physician is also involved, it should be examined to what extent resources can be made available for this task. Studies could, by the way, also show that practically all patients who decided for a DR were retrospectively satisfied with their decision [46] and that especially the younger patients felt the need for a further operation after mastectomy to improve the cosmetic result [47]. In general, it must be taken into consideration that patients may decide, even after intensive counselling and for personal reasons, against a DR and also a secondary reconstruction, this must of course be respected. Among the hospital characteristics merely the number of operations performed annually was associated with the performance of a DR: patients in hospitals where more than 200 primary cases per year were operated more frequently underwent a DR in comparison to patients in hospitals where 101-200 patients were operated annually. In analogy to the results of Hershman et al. (2012) the treatment volume is thus positively related to the probability of receiving a DR, whereby three other characteristics were also examined, namely the total number of beds in the hospital, the number of mastectomies per surgeon and the number of mastectomies per hospital. Relationships with the other examined characteristics and, in part, characteristics for the performance of DR reported in the literature such as teaching status [18, $22,35-37]$, operations per surgeon [22] and urbanity [18,19,22, 37] of the hospital's location could not be detected. This result is not surprising against the background of the high homogeneity of the investigated hospitals (all are DKG/DGS certified) and this can be considered as a positive influence of the German centre structure. Even so, a considerable proportion of variance between the hospitals in the model remains unexplained and poses the question as to what further factors play a role here at the hospital level (e.g., culture, qualification, QM). However, it must be conceded that the variable number of operations per surgeon considers solely the "main surgeons" and not all surgeons in the numerator and that, especially in academic teaching hospitals, assistant surgeons may also operate (albeit under the supervision of an experienced surgeon).

As in many previous studies the results of the analysis of data acquired retrospectively and in cross-section do not permit any direct causal conclusions to be drawn. On interpretation of the results it must be considered that they refer to specialised and certified breast cancer centres and that possibly the observed results may not be transferrable to less standardised facilities, whereby in Germany the latter are in the meantime in a clear minority. A comparison with not certified clinics would be interesting but is not possible on the basis of the present data. Furthermore, the transferability of results from Germany to other health-care systems is limited because of the reimbursement of hospital services via case-based flat rates. The authors of a cost-revenue analysis of direct reconstruction in Germany explain that, in the German diagnosis-related group (G-DRG) system, emphasis is on reimbursement-based incentives for separate interventions instead of a cost-covering financing of the direct reconstruction recommended in the guidelines [48]. The present investigation is more precise with regard to the time point of reconstruction than many of the previous studies because the necessary information was gathered from the treating hospital personnel and not as is often the case from quarterly claims data. The data provided by the hospital personnel about the clinical findings offer the advantages that not only stage but also the ASA classification are available. American studies, in contrast, usually consider only one of these characteristics. The response rate from the patient side was remarkably high and also the responses from key informants were above average. In spite of the comment in the questionnaire that, in the lack of personal knowledge, if necessary, colleagues should be consulted, evaluation of the apparently objective key numbers should be treated with caution. Altogether, previous studies can only be compared with one another and with our results with limitations due to the differing inclusion criteria and definition of DR.

\section{Implications for practice and research $\nabla$}

Even if the demonstrated inequalities in health care appear to be less than those in other countries there is still potential for improvement of equality in the management of mastectomy patients in Germany. Whereas the result that those with private insurance possibly have a better chance to receive a DR, perhaps due to financial incentives, should animate health-care politics to take appropriate action, the revealed relationship on the amount of information provided by physicians in hospitals suggests that also the health-care providers could contribute to a fairer supply. Higher case numbers are related to a higher probability to receive a DR, which can be interpreted as an argument in favour of minimum numbers.

Future studies should take the availability of plastic surgeons in the clinics more strongly into consideration. This was not possible in the present study. Furthermore, more attention should be paid to the reasons for a decision as well as to the question of who is to what extent involved in the decision-making process about the reconstruction time point, for example, by review of the patient records and under consideration of discussions of the tumour board. Thus, for example, it is not clear if older patients more frequently decide against a reconstruction or if the surgeons deliberately withhold information about the option or actively advise against it. In addition, a follow-up examination should be performed to accompany patients without DR. In this way it could be analyzed if they have not merely chosen a different time point for reconstruction or if they have possibly decided not to undergo any reconstruction.

\section{Acknowledgements \\ $\nabla$}

We thank the patients and the breast cancer centres for their active involvement in this study and the AVON company for generous support of the patient survey.

\section{Conflict of Interest \\ $\nabla$}

None.

\section{References}

1 Robert Koch-Institut; Gesellschaft der epidemiologischen Krebsregister in Deutschland e.V., Hrsg. Krebs in Deutschland 2009/2010. 9. Ausgabe. Berlin: 2013

2 Deutsche Krebsgesellschaft. Jahresbericht der zertifizierten Brustkrebszentren. 2014. Online: http://www.krebsgesellschaft.de/deutschekrebsgesellschaft-wtrl/deutsche-krebsgesellschaft/zertifizierung/ jahresberichte.html; http://www.onkozert.de/hinweise_zertifizierung _benchmarking.html; last access: 09.12.2014 
3 Kreienberg $R$, Albert US, Follmann M et al. Interdisziplinäre S3-Leitlinie für die Diagnostik,Therapie und Nachsorge des Mammakarzinoms. AWMF-Register-Nummer: 032-045OL - Kurzversion 3.0, Juli 2012. Geburtsh Frauenheilk 2013; 73: 1-28

4 Fernandez-Delgado J, Lopez-Pedraza MJ, Blasco JA et al. Satisfaction with and psychological impact of immediate and deferred breast reconstruction. Ann Oncol 2008; 19: 1430-1434

5 D'Souza N, Darmanin G, Fedorowicz Z. Immediate versus delayed reconstruction following surgery for breast cancer. Cochrane Database Syst Rev 2011; 7: CD008674

6 Petit JY, Gentilini O, Rotmensz N et al. Oncological results of immediate breast reconstruction: long term follow-up of a large series at a single institution. Breast Cancer Res Treat 2008; 112: 545-549

7 Begum S, Grunfeld EA, Ho-Asjoe $M$ et al. An exploration of patient decision-making for autologous breast reconstructive surgery following a mastectomy. Patient Educ Couns 2011; 84: 105-110

8 Morrow M, Mujahid M, Lantz PM et al. Correlates of breast reconstruction: results from a population-based study. Cancer 2005; 104: 23402346

9 Lang JE, Summers DE, Cui $\mathrm{H}$ et al. Trends in post-mastectomy reconstruction: a SEER database analysis. J Surg Oncol 2013; 108: 163-168

10 Schechter NR, Strom EA, Perkins GH et al. Immediate breast reconstruction can impact postmastectomy irradiation. Am J Clin Oncol 2005; 28 : 485-494

11 Hamahata A, Kubo K, Takei H et al. Impact of immediate breast reconstruction on postoperative adjuvant chemotherapy: a single center study. Breast Cancer 2013; DOI: 10.1007/s12282-013-0480-4

12 van Mierlo DR, Lopez Penha TR, Schipper RJ et al. No increase of local recurrence rate in breast cancer patients treated with skin-sparing mastectomy followed by immediate breast reconstruction. Breast 2013; 22: $1166-1170$

13 Bezuhly M, Temple C, Sigurdson LJ et al. Immediate postmastectomy reconstruction is associated with improved breast cancer-specific survival: evidence and new challenges from the Surveillance, Epidemiology, and End Results database. Cancer 2009; 115: 4648-4654

14 Zhong $T$, Fernandes KA, Saskin $R$ et al. Barriers to immediate breast reconstruction in the Canadian universal health care system. J Clin Oncol 2014; 32: 2133-2141

15 Deutsche Krebsgesellschaft; Deutsche Gesellschaft für Senologie. Erhebungsbogen für Brustkrebszentren. 2012. Online: http://www.senologie.org/brustzentren/zertififzierungsrichtlinien/; http://www.krebsgesellschaft.de/deutsche-krebsgesellschaft-wtrl/deutsche-krebsgesellschaft/zertifizierung/erhebungsboegen/organkrebszentren.html; last access: 09.12.2014

16 Joslyn SA. Patterns of care for immediate and early delayed breast reconstruction following mastectomy. Plast Reconstr Surg 2005; 115: $1289-1296$

17 Jeevan R, Cromwell DA, Browne JP et al. Regional variation in use of immediate breast reconstruction after mastectomy for breast cancer in England. Eur J Surg Oncol 2010; 36: 750-755

18 Reuben BC, Manwaring J, Neumayer LA. Recent trends and predictors in immediate breast reconstruction after mastectomy in the United States. Am J Surg 2009; 198: 237-243

19 Rosson GD, Singh NK, Ahuja N et al. Multilevel analysis of the impact of community vs. patient factors on access to immediate breast reconstruction following mastectomy in Maryland. Arch Surg 2008; 143 : 1076-1081; discussion 1081

20 Yang RL, Newman AS, Lin IC et al. Trends in immediate breast reconstruction across insurance groups after enactment of breast cancer legislation. Cancer 2013; 119: 2462-2468

21 Roder D, Zorbas H, Kollias J et al. Factors predictive of immediate breast reconstruction following mastectomy for invasive breast cancer in Australia. Breast 2013; 22: 1220-1225

22 Hershman DL, Richards CA, Kalinsky $\mathrm{K}$ et al. Influence of health insurance, hospital factors and physician volume on receipt of immediate post-mastectomy reconstruction in women with invasive and non-invasive breast cancer. Breast Cancer Res Treat 2012; 136: 535-545

23 Statistisches Bundesamt, Hrsg. Gemeindeverzeichnis-Sonderveröffentlichung: Gebietsstand: 31.12.2011. Alle politisch selbständigen Gemeinden in Deutschland nach Bevölkerung am 31.12.2011 auf Grundlage des Zensus 2011 und früherer Zählungen. Wiesbaden: Statistisches Bundesamt; 2013
24 Kowalski C, Wesselmann S, Kreienberg R et al. The patients' view on accredited breast cancer centers: strengths and potential for improvement. Geburtsh Frauenheilk 2012; 27: 137-143

25 Dillman DA. Mail and telephone surveys: the total design method. New York: Wiley \& Sons; 1978

26 Kowalski C, Würstlein R, Steffen $P$ et al. Vier Jahre Patientinnenbefragung im Rahmen der (Re-)Zertifizierung der Brustzentren in Nordrhein-Westfalen. Geburtsh Frauenheilk 2011; 71: 67-72

27 Kowalski C, Wesselmann S, Ansmann L et al. Key informants' perspectives on accredited breast cancer centres: results of a survey. Geburtsh Frauenheilk 2012; 72: 235-242

28 Sobin LH. TNM classification of malignant tumors (UICC). New York: Wiley; 2009

29 American Society of Anesthesiologists. ASA Physical Status Classification System. 2011. Online: https://www.asahq.org/For-Members/ClinicalInformation/ASA-Physical-Status-Classification-System.aspx; last access: 09.12.2014

30 Hox JJ. Multilevel Analysis. Techniques and Applications. New York: Routledge; 2010

31 Snijders TAB, Bosker RJ. Multilevel Analysis. An Introduction to basic and advanced multilevel Modeling. London: Sage; 1999

32 Kowalski C, Lee SY, Ansmann L et al. Meeting patients' health information needs in breast cancer center hospitals - a multilevel analysis. BMC Health Serv Res 2014; 14: 601

33 Agarwal S, Pappas L, Neumayer L et al. An analysis of immediate postmastectomy breast reconstruction frequency using the surveillance, epidemiology, and end results database. Breast 2011; 17: 352-358

34 Joslyn SA. Patterns of care for immediate and early delayed breast reconstruction following mastectomy. Plast Reconstr Surg 2005; 115: 1289-1296

35 Kruper L, Holt A, Xu XX et al. Disparities in reconstruction rates after mastectomy: patterns of care and factors associated with the use of breast reconstruction in Southern California. Ann Surg Oncol 2011; 18: $2158-2165$

36 Kruper L, Xu XX, Henderson $K$ et al. Utilization of mastectomy and reconstruction in the outpatient setting. Ann Surg Oncol 2013; 20: 828835

37 Sisco M, Du H, Warner JP et al. Have we expanded the equitable delivery of postmastectomy breast reconstruction in the new millennium? Evidence from the national cancer data base. J Am Coll Surg 2012; 215: 658-666; discussion 666

38 Hvilsom GB, Holmich LR, Frederiksen $K$ et al. Socioeconomic position and breast reconstruction in Danish women. Acta Oncol 2011; 50: 265-273

39 Parsons T. The social System. Glencoe: The Free Press; 1951

40 Say R, Murtagh M, Thomson R. Patients' preference for involvement in medical decision making: a narrative review. Patient Educ Couns 2006; 60: 102-114

41 Hubbard G, Kidd L, Donaghy E. Preferences for involvement in treatment decision making of patients with cancer: a review of the literature. Eur J Oncol Nurs 2008; 12: 299-318

42 Paasche-Orlow MK, Parker RM, Gazmararian JA et al. The prevalence of limited health literacy. J Gen Intern Med 2005; 20: 175-184

43 Lux MP, Maass N, Schütz F et al. Breast cancer 2013 - interpretation of new and known data. Geburtsh Frauenheilk 2013; 73: 584-598

44 Lux MP, Hildebrandt T, Bani $M$ et al. Health economic evaluation of different decision aids for the individualised treatment of patients with breast cancer. Geburtsh Frauenheilk 2013; 73: 599-610

45 Lux MP, Sell CS, Fasching PA et al. Time and resources needed to document patients with breast cancer from primary diagnosis to follow-up - results of a single-center study. Geburtsh Frauenheilk 2014; 74: 743751

46 Al-Ghazal SK, Sully L, Fallowfield L et al. The psychological impact of immediate rather than delayed breast reconstruction. Eur J Surg Oncol 2000; 26: 17-19

47 Bani MR, Beckmann K, Engel J et al. Correlates of desire for improved cosmetic results after breast conserving therapy and mastectomy in breast cancer patients. Breast 2008; 17: 640-645

48 Jacobs VR, Rasche L, Harbeck $N$ et al. Underfinancing of $90.3 \%$ for implant costs of prostheses and expanders in DRG revenues for uni- and bilateral mastectomy with immediate breast reconstruction. Onkologie 2010 ; 33: 584-588 